Article

\title{
The Role of Substrate Temperature and Magnetic Filtering for DLC by Cathodic Arc Evaporation
}

\author{
Helge Lux ${ }^{1, *}$, Matthias Edling ${ }^{1}$, Massimiliano Lucci ${ }^{2}{ }^{-}$, Julia Kitzmann ${ }^{3}$, Claus Villringer ${ }^{1}$, \\ Peter Siemroth ${ }^{4}$, Fabio De Matteis ${ }^{5}(\mathbb{D})$ and Sigurd Schrader ${ }^{1}$ \\ 1 Department of Engineering and Natural Sciences, Technical University of Applied Sciences Wildau, \\ Hochschulring 1, 15745 Wildau, Germany; edling@th-wildau.de (M.E.); villringer@th-wildau.de (C.V.); \\ schrader@th-wildau.de (S.S.) \\ 2 Department of Physics, University of Roma Tor Vergata, Via della Ricerca Scientifica, 1, 00133 Roma, Italy; \\ massimiliano.lucci@roma2.infn.it \\ 3 IHP Innovations for High Performance Microelectronics, Im Technologiepark 25, 15236 Frankfurt (Oder), \\ Germany; kitzmann@ihp-microelectronics.com \\ 4 Arc Precision GmbH, Schwartzkopffstraße 2, 15745 Wildau, Germany; siemroth@arcprecision.com \\ 5 Department of Industrial Engineering, University of Rome Tor Vergata, Via del Politecnico 1, \\ 00133 Rome, Italy; demattei@roma2.infn.it \\ * Correspondence: lux@th-wildau.de; Tel.: +49-337-550-8119
}

Received: 2 May 2019; Accepted: 23 May 2019; Published: 27 May 2019

check for updates

\begin{abstract}
Diamond-like carbon (DLC) films were deposited using two different types of high current arc evaporation. The first process used a magnetic particle filter to remove droplets from the plasma. For the second process, the samples were put into a metallic cage which was placed directly above the plasma source. For both processes, we varied the substrate temperature from 21 to $350{ }^{\circ} \mathrm{C}$ in order to investigate the temperature effect. The samples were characterized using SEM, AFM, XPS, Raman Spectroscopy, Ellipsometry, Photometry, and Nano Indentation in order to compare both methods of deposition and provide a careful characterization of such DLC films. We found that the $s p^{3}$ content and the hardness can be precisely adjusted by changing the substrate temperature. Furthermore, in the case of unfiltered deposition, the optical constants can be shifted in the direction of higher absorbance in order to produce black and hard carbon coatings.
\end{abstract}

Keywords: DLC; ta-C; arc evaporation; substrate temperature; hardness; optical constants; Ellipsometry

\section{Introduction}

Diamond-like carbon (DLC) films have attracted much attention due to their promising properties [1]. Because of high content of $s p^{3}$-hybridized carbon bonds (diamond bonding), the coating provides a high hardness, high electrical resistivity, good thermal conductivity, and chemical inertness. Hence, DLC coatings can be used for a wide range of applications, for example, for biological purposes [2] in microelectronics [3] and for wear-protection [4,5]. Additionally, DLC can be applied as a coating with a low coefficient of friction (COF) to enhance the tribological behavior of the substrate material [6,7]. Moreover, different DLC coatings were tested as coatings for manufacturing (drilling) aluminum and aluminum alloys [8,9]. Nevertheless, the coating has to be adapted to each possible application in order to optimize the adhesion, electrical conductivity, density, hardness, and optical constants. Therefore, many deposition methods were developed for the production of different types of DLC. Using Chemical Vapor Deposition (CVD) or Plasma Enhanced CVD (PECVD) $[10,11]$ the resulting coating always contains hydrogen and the so called hydrogenated tetrahedral amorphous carbon (ta-C:H) can be produced. Here, the hydrogen originates from the carbon containing precursor gas and 
the hydrogen content of the growing film can be adjusted by choosing precursor gases with different hydrogen concentrations, such as methane $\left(\mathrm{CH}_{4}\right)$, acetylene $\left(\mathrm{C}_{2} \mathrm{H}_{2}\right)$, or cyclohexane $\left(\mathrm{C}_{6} \mathrm{H}_{12}\right)$ [12]. Typically, hydrogen can increase the electrical resistivity of the DLC films but also decreases the hardness. By using PECVD in a pulsed mode, it is possible to increase the deposition rate and reduce the compressive stress as well as improve the adhesion [13].

To deposit hydrogen-free ta-C, it is necessary to use physical vapor deposition (PVD) where the carbon originates from a solid carbon source without using any hydrogen containing atmosphere. Established PVD methods are conventional magnetron sputtering [14], Pulsed Laser Deposition [15], and Arc Evaporation. The latter can work with DC current or in a pulsed mode, such as a Laser Arc [16] or High Current Arc (HCA) [17]. The HCA technique uses plasma pulses up to 3000 A and can produce carbon coatings with very high hardness and density because of the higher content of $s p^{3}$-hybridized carbon bonding, compared to other methods described above. In the case of using an optional magnetic macro particle filter $(\Phi-\mathrm{HCA})$, the plasma and the coating are nearly free of droplets. Due to the so called sub-plantation process, where the impinging carbon ions penetrate the substrate and subsequently the growing carbon layer, the structure of the film is amorphous without any island growth. The $\Phi-H C A$ technique was developed to produce, for example, ultra-hard hydrogen-free tetrahedral amorphous carbon (ta-C) for magnetic storage disks and read-write-heads in order to avoid damage and corrosion [18].

Due to their high hardness, such coatings can probably be used as wear-protective coatings for optical parts, for example, lamellas in iris diaphragms. They can avoid scratches and polishing effects during thousands of open-close cycles and reduce the corrosion of the lamellas. However, for applications in cameras, microscopes, and other optical applications, the direct and total reflectance of the diaphragm should be as low as possible in order to avoid ghost images. Consequently, for such applications, a hard and black coating with low direct reflectance is desirable. Typically, ta-C coatings provide a refractive index of about 2.6 and extinction near zero for a wide range of electromagnetic radiation, from UV to NIR. Consequently, these coatings are transparent and show interference colors in dependence of the layer thickness. Moreover, this kind of carbon coating provides a relatively high compressive stress, which can cause adhesion problems and deform thin and soft samples.

For this work, we modified the method of deposition to increase the extinction and decrease the refractive index, resulting in a black and hard carbon coating. Subsequently, we compared hardness, optical constants, and $s p^{3}$ content of the modified coating with that of conventional ta-C by $\Phi-H C A$.

\section{Methods of Characterization}

The hardness was measured using Nano indentation (Nano Test, Micro Materials Ltd., Wrexham, UK) with a maximum load of $1 \mathrm{mN}$ and indentation depth of about $30 \mathrm{~nm}$ using a diamond Berkovitch tip. The operating parameters for this setup are reported in Table 1.

Table 1. Operating parameters for nano indentation measurements.

\begin{tabular}{cc}
\hline Parameter & Value \\
\hline Maximum load & $1 \mathrm{mN}$ \\
Time of maximum fixed load & $10 \mathrm{~s}$ \\
Indentation depth & $30 \mathrm{~nm}$ \\
Penetration speed/load control & $0.05 \mathrm{mN} / \mathrm{s}$ \\
Matrix & $3 \times 3$ \\
Type of indenter probe & Diamond Berkovitch \\
\hline
\end{tabular}

The roughness and topography of the surface was investigated using AFM (AutoProbe CP, PSI, Sunnyvale, CA, USA) and SEM (JSM-6510, JEOL, Tokyo, Japan). The optical constants were measured using Spectral Ellipsometry (Sentech SENresearch SE 800, Berlin, Germany). Investigation on total reflection was done using Spectral Photometry (Perkin Elmer Lambda 1050, Waltham, MA, USA). 
To examine the different carbon allotropes, Raman spectroscopy (WITec Alpha 300, Ulm, Germany) with an excitation wavelength of $488 \mathrm{~nm}$ and XPS (PHI VersaProbe II, Physical Electronics, Chanhassen, MN, USA) were used. For calibrating the growth rate, the thickness of the carbon coatings was measured after a certain count of plasma pulses on an edge using Profilometry (Veeco DEKTAK, Plainview, NY, USA).

\section{Experimental Setup}

We used two different coating processes to prepare the samples (grown on polished silicon wafers). The first process used a conventional magnetic filtered arc evaporation set-up, described in more detail elsewhere $[17,19]$, where the substrates were fixed on a rotating planar sample holder. The evaporator worked in a pulsed mode using $1.0 \mathrm{~ms}$ pulses with an arc current of up to $3000 \mathrm{~A}$. The transmission of the filter module was changed by choosing different filter currents up to $800 \mathrm{~A}$. The angle of incidence of the plasma beam was $0^{\circ}$ with respect to the surface normal, resulting in a maximum impinging energy of the carbon ions (Figure 1a).

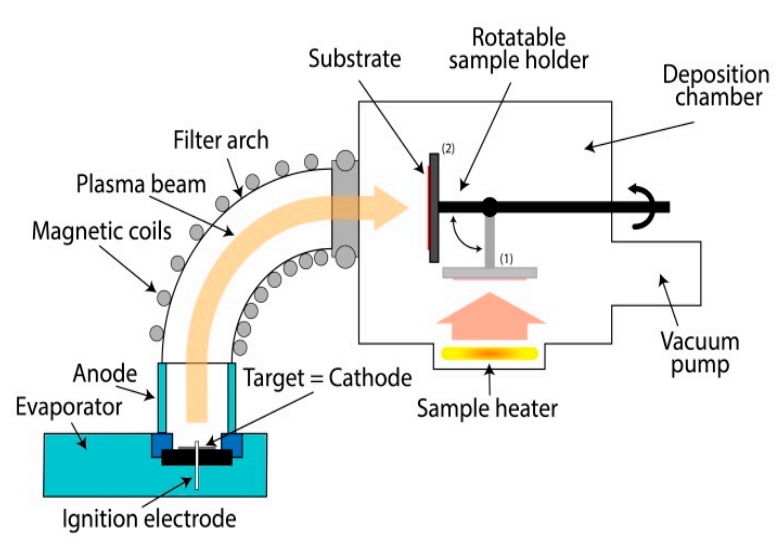

(a)

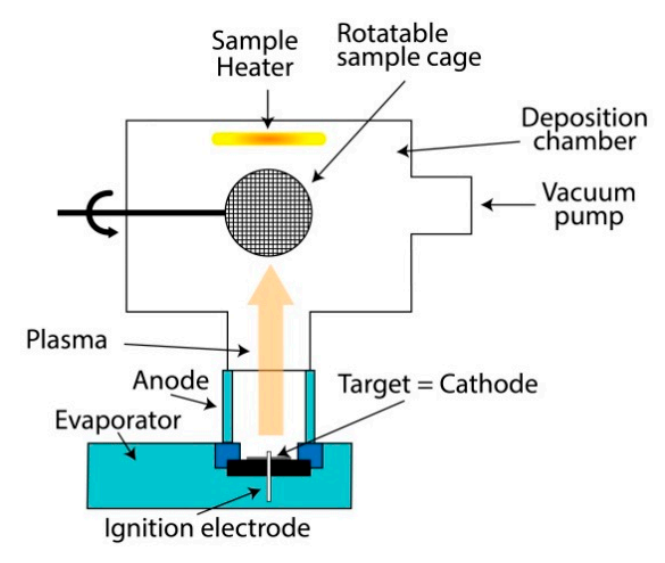

(b)

Figure 1. Experimental setup (a) with magnetic filtering, (b) without filter module with rotating metallic cage.

For the second process, we modified the experimental setup to combine the high current arc evaporation with a rotating metallic cage. The cage was made of metallic mesh with a transmittance of $70 \%$ and it was positioned directly above the plasma source (Figure 1b). During the deposition, the carbon ions passed though the electrically grounded metallic mesh of the rotating cage to coat the samples inside. Due to the permanent movement of the samples inside the cage, the angle of incidence of the plasma beam varied from 0 to $90^{\circ}$, resulting in a decreasing average impinging energy compared to the setup with the magnetic filter module. This caused a lower amount of $s p^{3}$ carbon resulting in a lower hardness and different optical properties of the DLC coating. Additionally, the grounded mesh can cause several processes, which can potentially disturb the coating process. On the one hand, the cage can shield the electrical potential or parasitic retarding fields can moderate the particle energy, resulting in a lower $s p^{3}$-content and reduced hardness of the coating. On the other hand, high energetic carbon ions can cause sputtering processes on the metallic mesh. This can extract metal atoms, which subsequently reach the surface of the samples. These kinds of impurities can also reduce the quality of the carbon coating, but they can be observed by an ex situ material analysis.

Table 2 shows the process parameters for the DLC production that were kept constant for both processes. 
Table 2. Process parameters for the diamond-like carbon (DLC) production.

\begin{tabular}{ccc}
\hline Parameter & Value (Filtered) & Value (Cage) \\
\hline Arc current & $3000 \mathrm{~A}$ & $3000 \mathrm{~A}$ \\
Filter current & $600 \mathrm{~A}$ & - \\
Pulse duration & $1 \mathrm{~ms}$ & $1 \mathrm{~ms}$ \\
Pulse frequency & $5 \mathrm{~Hz}$ & $5 \mathrm{~Hz}$ \\
Deposition rate & $0.15 \mathrm{~nm} /$ pulse & $0.125 \mathrm{~nm} / \mathrm{pulse}$ \\
Pulse count & 500 & 600 \\
Base pressure & $10^{-4} \mathrm{~Pa}$ & $10^{-4} \mathrm{~Pa}$ \\
\hline
\end{tabular}

In both processes, the samples were pre-heated using a $300 \mathrm{~W}$ halogen lamp with a DC voltage of $200 \mathrm{~V}$. The temperature was measured using a thermo-couple placed directly on the sample in the case of magnetic filtering and on the metallic cage in the case of no filtering. The thickness of the coating was kept constant at $75 \mathrm{~nm}$. The temperature of the samples before coating was varied between room temperature (no heating) and $350^{\circ} \mathrm{C}(5 \mathrm{~min}$ pre-heating).

For setting the different samples into the metallic cage, it could be opened easily in the middle. This method allowed an effective coating of more than 100 samples simultaneously, depending on the size of the sample cage. For rotation, the cage was connected with a pivoted shaft. Figure 2 shows the cage with samples inside closed (a) and opened (b).

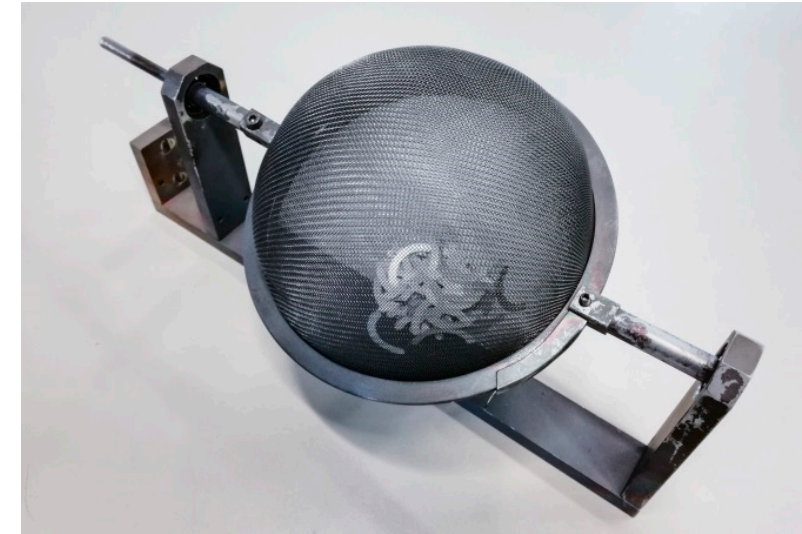

(a)

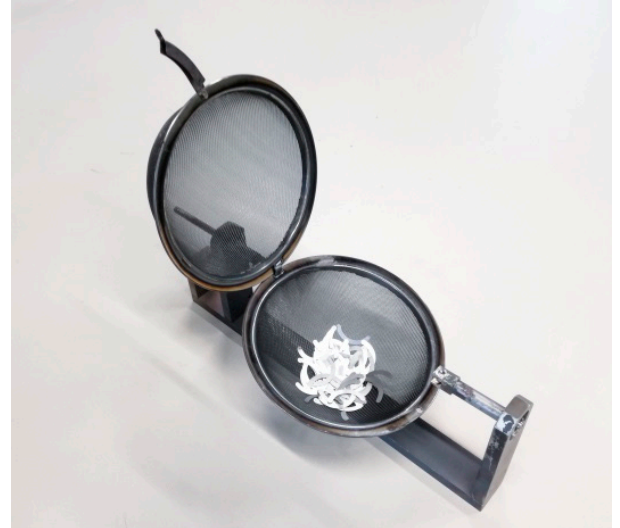

(b)

Figure 2. Pivoted sample cage with samples: closed (a) and opened (b).

\section{Results}

\subsection{Topology}

To investigate the topology of the samples and the effect of the pre-heating, the surface was characterized using AFM and SEM. Figure 3 shows the AFM pictures and SEM photographs for the magnetic filtered process $(\mathrm{a}, \mathrm{c})$ and the unfiltered process $(\mathrm{b}, \mathrm{d})$ with the samples inside the cage. It can easily be seen that the magnetic filter effectively reduced the number of particles. Consequently, the surface had a low intrinsic roughness of $0.4 \mathrm{~nm}$ RMS, equal to that of the substrate material (polished silicon wafer). As expected, the roughness of the surface increased by coating without the filter module. In this case, all droplets and agglomerations, which were produced by the arc discharge, were undisturbed past the metallic mesh of the cage and subsequently reached the surface. 


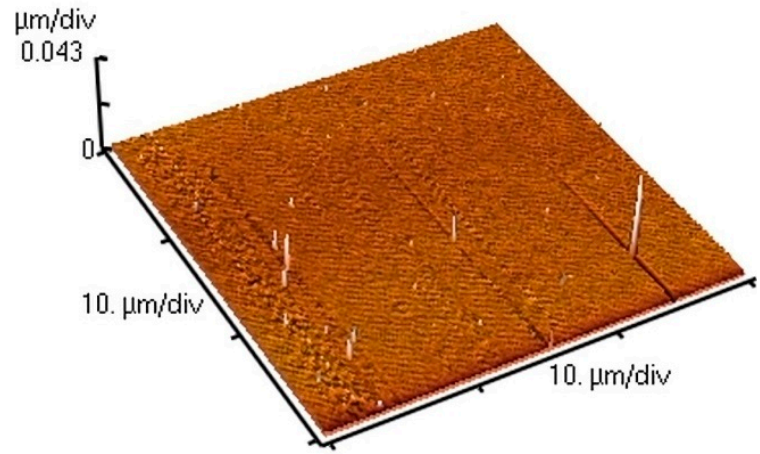

(a)

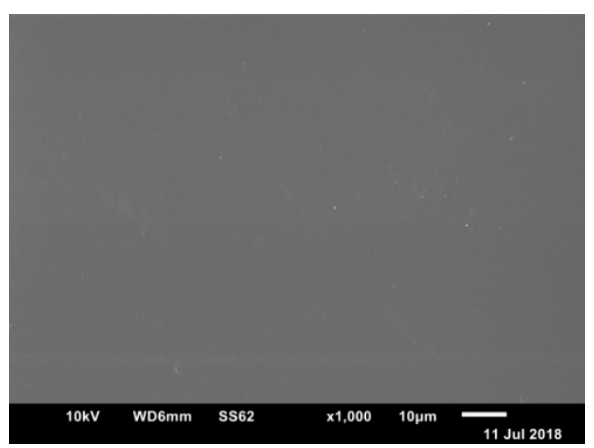

(c)

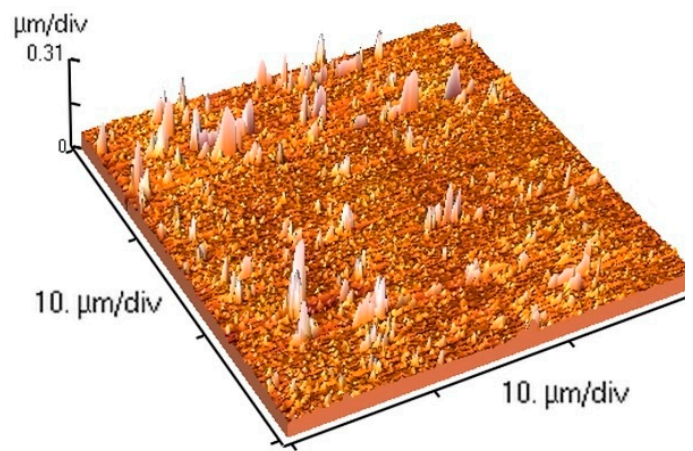

(b)

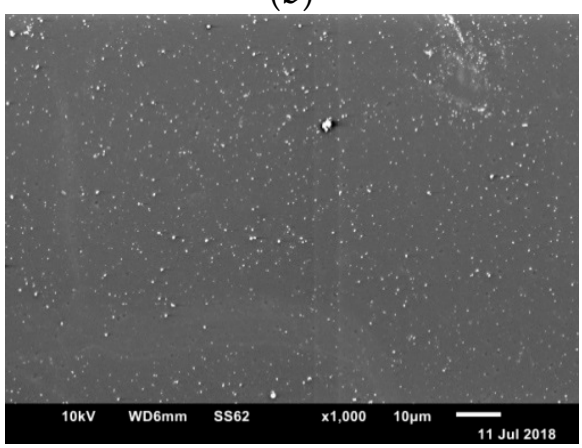

(d)

Figure 3. AFM picture of ta-C (a) using magnetic filtering and (b) without the filter module. SEM picture of ta-C (c) using magnetic filtering and (d) without the filter module.

Hence, the roughness was higher compared to the coating resulting from magnetic filtered plasma and reached $10 \mathrm{~nm}$ RMS. In AFM and SEM pictures of the surface, the droplets and the increased roughness of the sample can easily be identified. In contrast, an increase of the substrate temperature did not influence the roughness of the resulting coating. In all cases, the roughness was low enough to conduct optical measurements (Ellipsometry) as well as nano indentation. A comparison of the roughness between this work and other established coatings from the literature is provided in Table 3:

Table 3. RMS roughness of DLC produced using different deposition techniques.

\begin{tabular}{ccc}
\hline Method & RMS Roughness (nm) & Reference \\
\hline Magnetron sputtering & $0.2-0.7 \mathrm{~nm}$ & {$[20]$} \\
Cathodic Arc & $0.1-1.3 \mathrm{~nm}$ & {$[20]$} \\
PECVD & $0.1-2.5 \mathrm{~nm}$ & {$[10]$} \\
$\Phi-H C A$ (this work) & $0.4 \mathrm{~nm}$ & - \\
Unfiltered HCA (this work) & $10 \mathrm{~nm}$ & - \\
\hline
\end{tabular}

These roughness values are in good accordance to the literature. As described above, the surface roughness of the unfiltered ta- $C$ was much higher due to the bombardment of droplets and agglomerations, which can also pass through the metallic mesh of the cage.

The SEM cross-section photograph of the magnetic filtered ta-C (Figure 4) shows a carbon coating with a very low roughness and an excellent adhesion due to the amorphous character of the material and high portion of diamond-carbon bonds. 


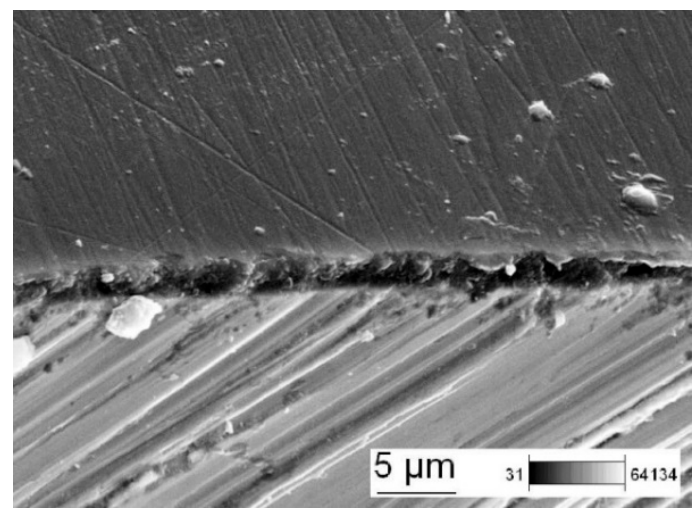

Figure 4. SEM cross section photograph of ta-C produced using magnetic filtered arc evaporation.

\subsection{Hardness Measurements}

For industrial application (e.g., as wear-protective coating), the mechanical properties of the carbon coatings (hardness, Young Modulus) are important factors. For the current investigation, we measured the hardness by means of nano indentation of the samples, coated under different substrate temperatures.

Due to several problems of using nano indentation for hard coatings on softer surfaces [21], the real hardness of the coatings can be higher than what was measured here [22]. This effect is known from the literature, especially for thin DLC coatings, providing a thickness of less than $100 \mathrm{~nm}$. In this case, the indentation measurement was not independent from the surface [22]. However, for the current investigation, we kept the thickness and all coating parameters constant to show a qualitative effect of the substrate temperature on the mechanical properties of the DLC coating.

Figure 5 shows the measured layer hardness versus the coating temperature for both coating processes described above (filtered, cage). Each data point is an average value of nine independent and randomly chosen measurement points.

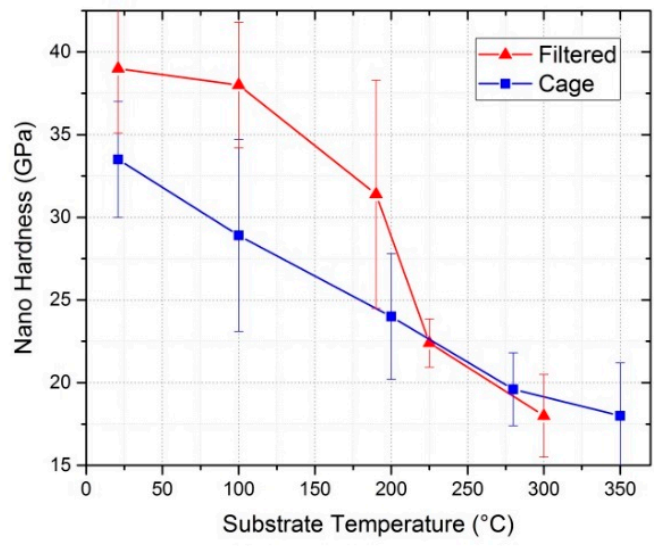

Figure 5. Hardness versus the coating temperature for filtered deposition (red triangle) and unfiltered deposition (blue square).

As expected, the hardness of the coating decreased with increasing substrate temperature due to the higher level of graphitization. Based on the higher average impinging energy of the carbon ions in case of filtered deposition, the resulting hardness of the coating at room temperature was higher compared to the deposition in a rotation cage. Furthermore, as described above, different electrical potentials inside and outside the metallic cage can also reduce the impinging particle energy, resulting in a lower hardness. At higher substrate temperatures above $200{ }^{\circ} \mathrm{C}$, the influence of the temperature 
seems to compensate for these effects of the impinging energy and, consequently, the values for hardness converge.

\subsection{Optical Properties}

For optical investigation, the ta-C coatings were measured ex-situ after deposition using Spectral Ellipsometry and Spectral Photometry. The ellipsometric parameters Psi and Delta were recorded at wavelengths ranging from 190 to $980 \mathrm{~nm}$ and at five angles between $50^{\circ}$ and $70^{\circ}$. The fit was conducted for the spectra range of 250-980 $\mathrm{nm}$ using two Tauc-Lorentz oscillators for the ta-C layer.

Surprisingly, we recognized a strong difference between the two coating processes. Figure 6 shows the optical constants (refractive index $n$, extinction coefficient $k$ ) for the samples, coated under varied substrate temperatures.

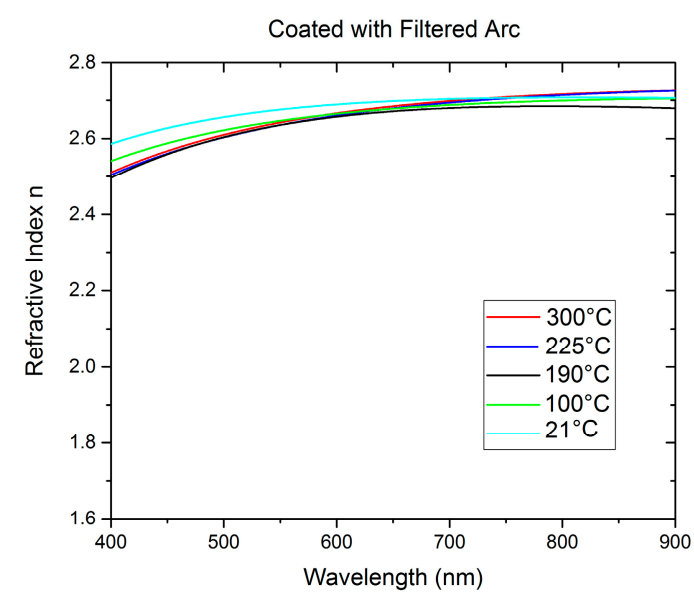

(a)

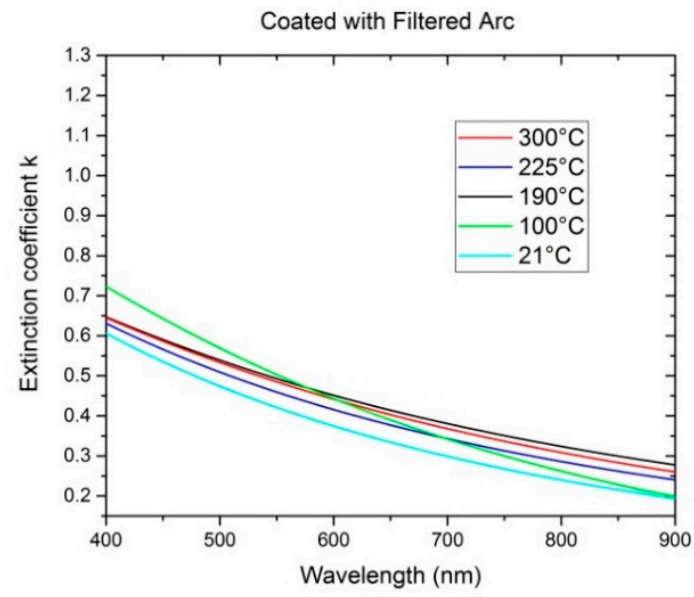

(c)

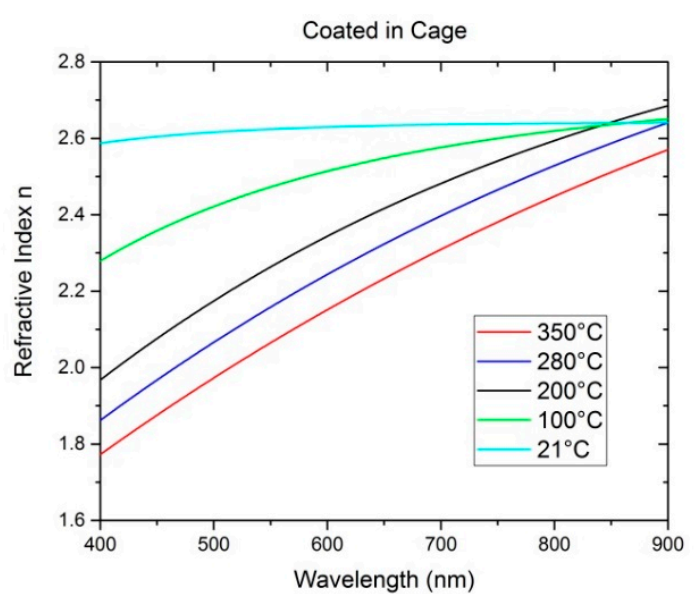

(b)

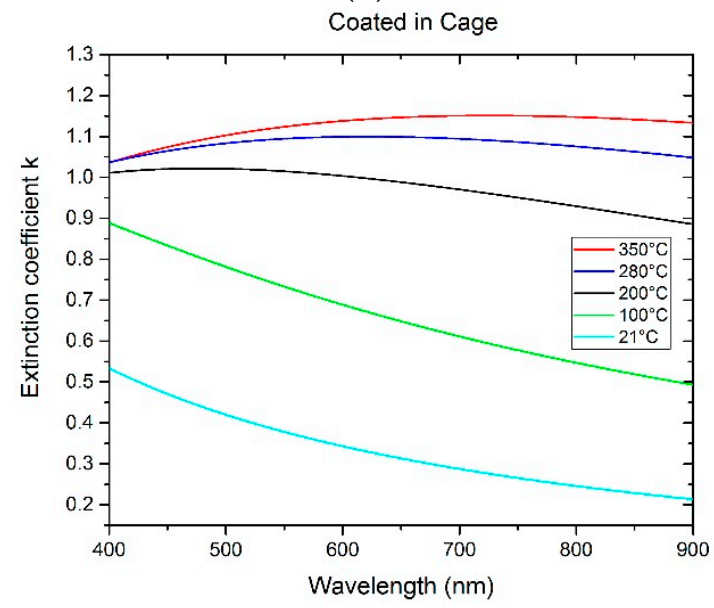

(d)

Figure 6. Optical constants for ta-C at different coating temperatures: $(\mathbf{a}, \mathbf{c})$ filtered arc, $(\mathbf{b}, \mathbf{d})$ coated in rotating cage.

In the case of magnetic filtering (Figure 6a,c), no significant changes in optical constants were seen. This was unexpected based on the literature, where a strong influence of the substrate temperature on the refractive index and the extinction coefficient was described [16]. However, the refractive index of about 2.6 is much higher than reported in the literature for magnetron sputtering [14] and Laser Arc [16], indicating the presence of diamond bonds to a large extent. 
In contrast, when using the rotating cage, we observed a strong decrease of the refractive index by increasing the coating temperature (Figure 6b). Additionally, the extinction coefficient increased to reach the maximum at the highest coating temperature. Both effects can be explained by a progressive graphitization at higher coating temperatures (Figure $6 \mathrm{~d}$ ). A higher portion of $s p^{2}$-hybridized carbon will cause a higher absorption and simultaneously decrease the refractive index from diamonds in the direction of graphite.

To summarize the ellipsometric results, Figure 7a,b shows the optical constants (refractive index $n$ (a) and absorption $k(b))$ at $633 \mathrm{~nm}$ for samples grown by the two different processes.

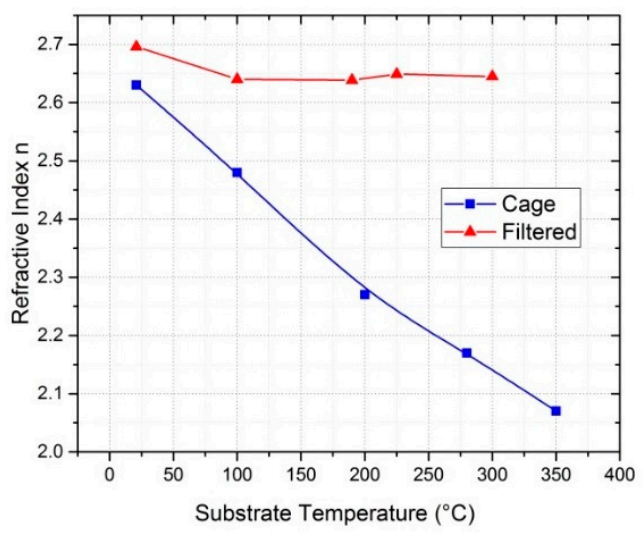

(a)

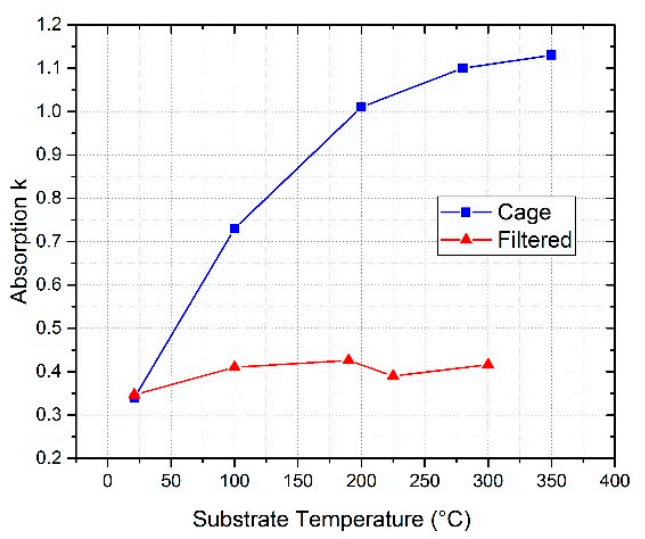

(b)

Figure 7. Optical constants for ta-C: (a) refractive index $n$ and (b) extinction coefficient $k$ for samples grown by filtered deposition (red triangles) and unfiltered deposition in a cage (blue rec).

As described above, to use the DLC as a black and wear-protective coating, the spherical and direct reflection should be as low as possible. Therefore, two different parameters should be optimized: On the one hand, the coating should have a high optical absorption (extinction coefficient) that is more or less independent of the incident wavelength of light. On the other hand, to avoid a strong direct reflection, the coating (or the substrate) should have a macroscopic roughness and a low refractive index $n$. As shown above, these requirements can be fulfilled by using a rotating metallic cage instead of a planar sample holder and by pre-heating up to $350^{\circ} \mathrm{C}$.

For the investigation of reflectance, we coated stainless-steel foils (lamellas for iris diaphragms) instead of silicon wafers with more than 20 samples simultaneously in the rotating metallic cage without any sample holder and the total reflection of the samples was measured before and after deposition by means of Spectral Photometry. Figure 8a shows the results of this investigation. As expected, the uncoated steel had a high total reflection that increased with higher wavelengths. After deposition, the samples had a homogeneous black coating without any uncoated regions (Figure $8 \mathrm{~b}$ ). Due to the simultaneous deposition on both sides of the sample inside the rotation cage, the internal stress of the ta- $\mathrm{C}$ can be compensated. Hence, even a thin metal foil will not be deformed after the plasma process.

The total reflection of the coated samples was lower than $10 \%$ from UV to NIR. The dispersion was linear and the dependence on the wavelength of light from UV to NIR was weak, resulting in a black coating. 


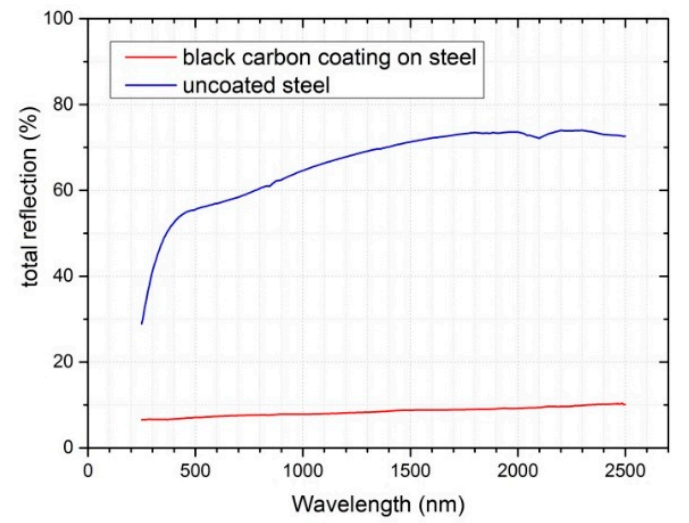

(a)

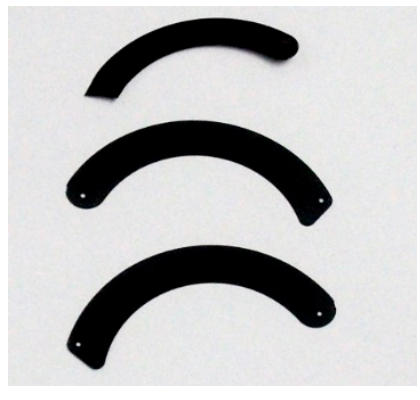

(b)

Figure 8. (a) Spherical reflection of uncoated stainless-steel (blue line) and pre-treated (roughened) and coated stainless-steel (red line); (b) Photograph of coated lamellas for the production of iris diaphragms.

\subsection{XPS Measurements}

Using XPS measurements, the absolute $s p^{2} / s p^{3}$ ratio can be calculated by a deconvolution of the $\mathrm{C}$ 1s-peak in high resolution $[23,24]$. The $\mathrm{C} 1$ s peak consists of peaks due to $s p^{3}$-carbon $(285.2 \mathrm{eV})$, $s p^{2}$-carbon $(284.4 \mathrm{eV})$, and CO-contamination $(286.5 \mathrm{eV})$, which can be caused by the oxygen residuals inside the vacuum chamber. Additionally, the presence of metal impurities can be identified by analyzing the XPS surface scan. For the current investigations, Figure 9 shows a surface scan (a) and the high resolution $C 1$ s peak (b) with its deconvoluted compounds. As an exemplary model for all XPS measurements, the spectrum of the filtered arc coating at $190^{\circ} \mathrm{C}$ is shown. The deconvoluted $\mathrm{C} 1 \mathrm{~s}$ peaks for all measurements are presented in the supplementary information at Figure S1a-j).

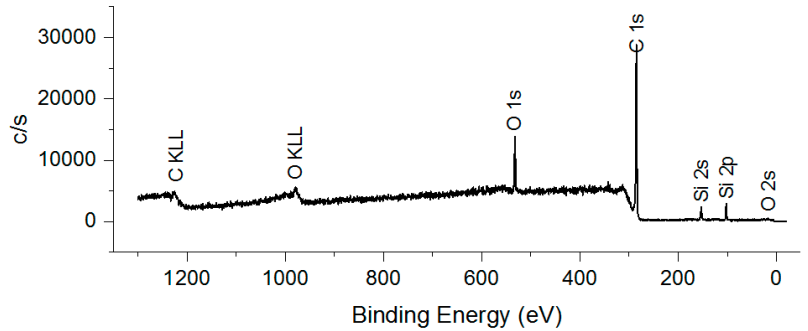

(a)

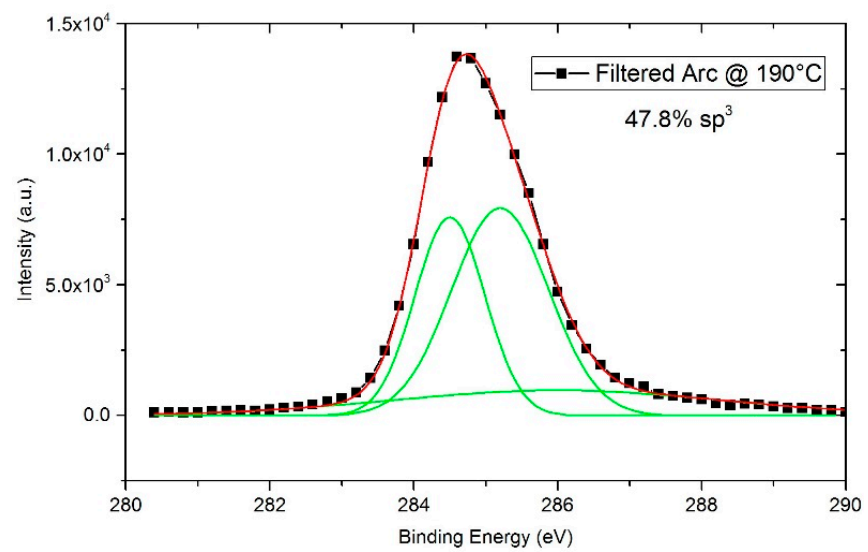

(b)

Figure 9. (a) XPS surface scan of DLC, (b) XPS C 1s peak from DLC with its deconvoluted compounds for $s p^{3}$-carbon $(285.2 \mathrm{eV}), s p^{2}$-carbon $(284.4 \mathrm{eV})$, and C-O contamination $(286.5 \mathrm{eV})$. 
The surface scan shows no impurities or metal contamination, which can be caused by the sputtering processes on the metallic mesh of the cage. The silicon peaks originate from the substrate material due to the relatively low carbon thickness of $75 \mathrm{~nm}$. Additionally, the spectrum shows no sign of $\mathrm{SiC}$, which should appear at $283.7 \mathrm{eV}$. The $\mathrm{C}-\mathrm{O}$ contamination is quite constant for each sample and comparable to other deposition techniques.

To compare the $s p^{2} / s p^{3}$ ratio of the carbon coating by varying the temperature of the substrate, Figure 10 shows the percentage of diamond bonds from XPS measurements (deconvolution of C 1s) for the different samples. The $s p^{3}$-content of the coating strongly decreased with increased substrate temperature. Additionally, the $s p^{3}$-content of the samples coated with the magnetic filtered arc was higher than that of the cage-coated samples. Similar to the hardness measurements, this can be explained by the higher average impinging energy of the carbon ions. In good correlation to the hardness, this effect decreased with increased substrate temperature.

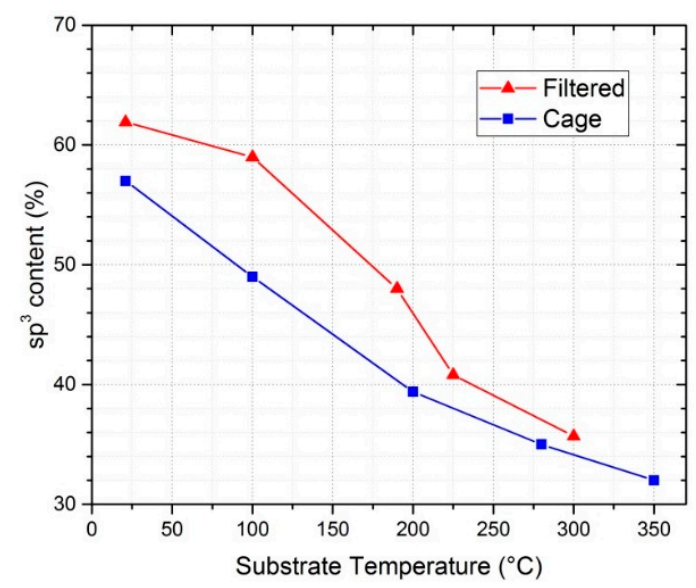

Figure 10. The $s p^{3}$ content, calculated from XPS measurements for DLC coatings, coated under different substrate temperatures. Magnetic Filtered Arc (red triangles), coated in rotating cage (blue squares).

\subsection{Raman Spectroscopy}

To investigate the composition of different carbon coatings, Raman spectroscopy can be used. In the case of ta-C, only two bands were visible in the Raman spectrum: The D band at $\sim 1350 \mathrm{~cm}^{-1}$ and the $\mathrm{G}$ band at $\sim 1580 \mathrm{~cm}^{-1}$. The $\mathrm{G}$ band relates to the graphitic part of the coating whereas the $\mathrm{D}$ band represents the distortion of the graphitic order. Hence, the D band is closely connected to the $s p^{3}$ content of the carbon coating. However, using Raman spectroscopy at visible wavelength, the $s p^{3}$-bonds of the carbon coating cannot be excited due to the high band gap of $s p^{3}$-hybridized carbon. Only the ratio of the intensities from the $\mathrm{D}$ band $I(\mathrm{D})$ and the $\mathrm{G}$ band $I(\mathrm{G})$ for visible Raman spectroscopy can give some information about the $s p^{2} / s p^{3}$ ratio $[25,26]$. Generally, we expect an increasing $I(\mathrm{D}) / I(\mathrm{G})$ ratio with higher substrate temperature (higher content of $s p^{2}$-hybridization) in the case of amorphous carbon without crystallinity. The $I(\mathrm{D}) / I(\mathrm{G})$ ratio can be calculated by a deconvolution of the broad Raman band between 1000 and $1800 \mathrm{~cm}^{-1}$. For the analysis, we used the most established Breit-Wigner-Fano (BWF) line for the G peak and a Lorentzian fit for the D peak [26]. Figure 11a shows a typical Raman spectrum of the characterized carbon coating, the D band and the G band (green line), and the resulting fit curve (red). All Raman measurements and the deconvolution of the D and G bands are presented in the supplementary information at Figure S2a-j). 


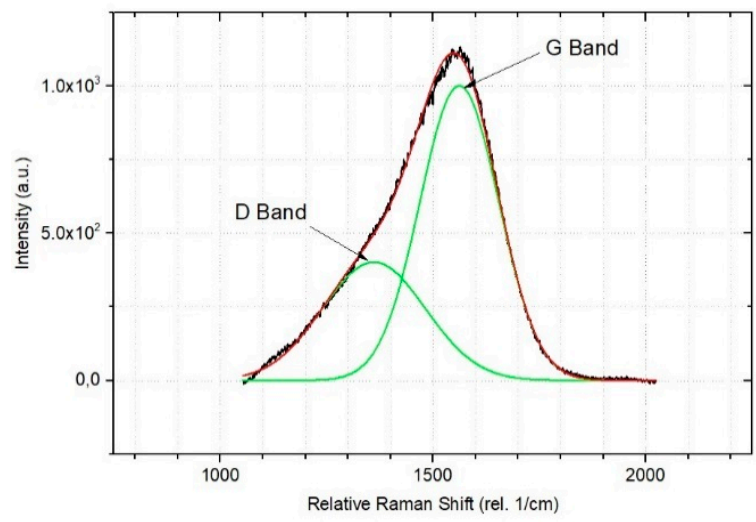

(a)

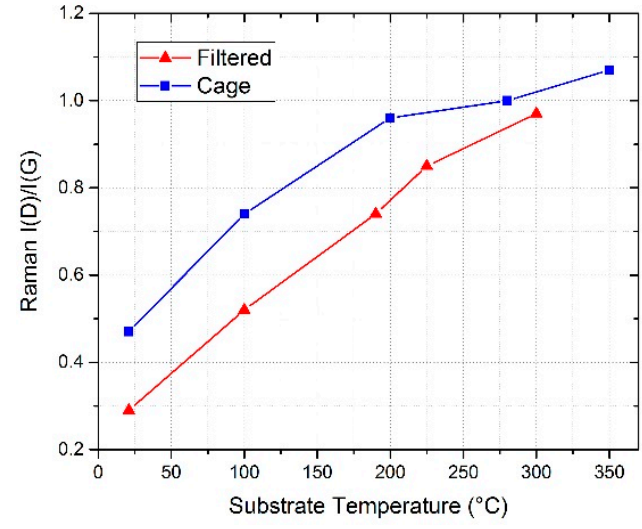

(b)

Figure 11. (a) Deconvolution of the Raman D and G bands (green line) and the resulting fitting curve (red line); (b) Raman $I(D) / I(G)$ ratio vs. substrate temperature for filtered deposition (triangle) and unfiltered deposition (square).

It can easily be seen in Figure $11 \mathrm{~b}$ that the $I(\mathrm{D}) / I(\mathrm{G})$ ratio increases with higher substrate temperature, indicating a fundamental change in the structure of the DLC film due to increasing graphitization.

\section{Discussion}

In summary, we found that the properties of ta-C deposited using high current arc evaporation can be fundamentally changed by increasing the substrate temperature during the process. That fact applies for both examined processes: the magnetic macro particle filtering as well as the metallic cage. Especially, the $s p^{2} / s p^{3}$ ratio can be adjusted by changing the substrate temperature. In good correlation to the literature [24], this results in a linear relationship of $s p^{3}$-content and hardness, which can be seen in Figure 12a. Moreover, both processes fit nearly in the same line showing that the hardness of DLC is closely connected to the portion of $s p^{3}$-hybidized carbon. The red and the blue lines in Figure 12a,b represent a linear fit of the measured values. These results are also in excellent accordance with previous works $[24,27]$.

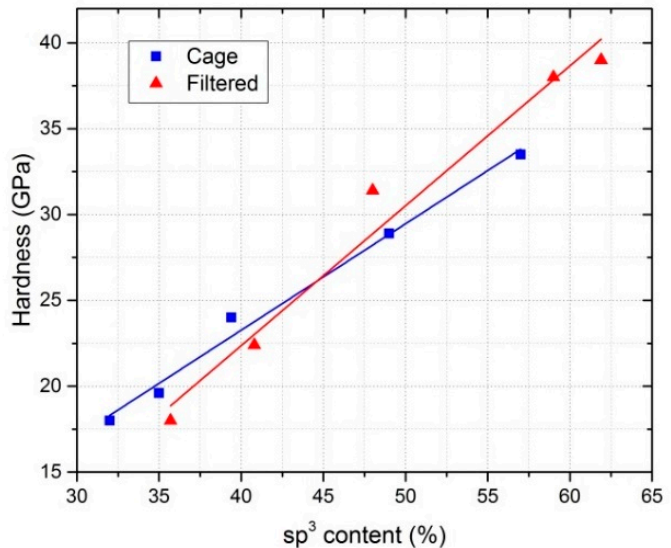

(a)

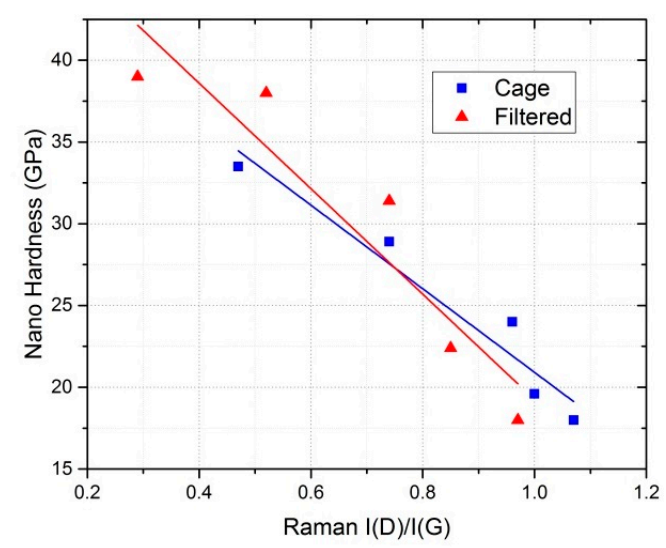

(b)

Figure 12. (a) Hardness versus $s p^{3}$-content for filtered deposition (red triangle) and unfiltered deposition in a metallic cage (blue square); (b) Raman $I(D) I(G)$ versus hardness. Red and blue lines: Linear fit of the measured values.

Additionally, due to the strong correlation between the Raman $I(\mathrm{D}) / I(\mathrm{G})$ ratio and $s p^{3}$-content, both the hardness and the $\mathrm{sp}^{3}$-content can be examined only by using visible Raman spectroscopy 
(Figure 12b). This finding was recently published for annealed coatings at different temperatures [28], but now we can verify this effect even for different substrate temperatures during the deposition process.

As described above, the hardness of the DLC coatings decreases at higher substrate temperatures. At room temperature, the hardness is about $38 \mathrm{GPa}$ for the $\Phi$-HCA process and $34 \mathrm{GPa}$ for coating in metallic cage. These values are in the same range as the results, arising from different coating processes with similar $s p^{3} / s p^{2}$ ratios [22]. At maximum substrate temperature, the black carbon coating provides a reduced hardness of about $18 \mathrm{GPa}$. This is much lower than when coated at room temperature but still near to other established hard metal nitrides [29-32]. A comparison of our coatings to those from the literature is provided in Table 4.

Table 4. Hardness of metal nitrides and different DLC coatings.

\begin{tabular}{ccc}
\hline Material & Hardness $\boldsymbol{H}$ (Gpa) & Reference \\
\hline TiN & 25.5 & {$[29]$} \\
$\mathrm{CrN}$ & 25.8 & {$[29]$} \\
$\mathrm{TiAlN}$ & 26.3 & {$[29]$} \\
$\mathrm{Cr}{ }_{2} \mathrm{~N}$ & 28 & {$[30]$} \\
$\mathrm{TiAlN}$ & 35 & {$[31]$} \\
$\mathrm{TiN}$ & 25 & {$[32]$} \\
DLC $(\mathrm{DC}$ Arc $)$ & 45 & {$[24]$} \\
$\mathrm{DLC}(\mathrm{PECVD})$ & 35 & {$[33]$} \\
ta-C $(\Phi-\mathrm{HCA})$ & $60-90$ & {$[18]$} \\
ta-C $(\Phi-\mathrm{HCA})$ & $38-60$ & {$[22]$} \\
ta-C $(\Phi-\mathrm{HCA}) @ 21^{\circ} \mathrm{C}$ & 38 & This work \\
ta-C $(\Phi-\mathrm{HCA}) @ 300{ }^{\circ} \mathrm{C}$ & 18 & This work \\
DLC $($ Cage $) @ 2{ }^{\circ} \mathrm{C}$ & 34 & This work \\
DLC $($ Cage $) @ 350^{\circ} \mathrm{C}$ & 18 & This work \\
\hline
\end{tabular}

With the optical investigation, we found that only when using the metallic cage did the refractive index and the extinction coefficient change by varying the substrate temperature. Due to the higher portion of graphite at higher temperatures, the refractive index $n$ decreases and the absorption $\mathrm{k}$ increases. This strong correlation between $s p^{3}$-content and optical constants was also described in the literature for DLC, produced using PLD with different laser energies [34]. A higher absorption results in a lower reflection, for which reason this coating can be used as black and wear-protective material. However, in sharp contrast to that result, we found no clear dependence of the optical constants and substrate temperature in the case of using the magnetic macro particle filter. Both the refractive index $\mathrm{n}$ and the extinction $\mathrm{k}$ are quite constant. In contrast, the Raman $I(\mathrm{D}) / I(\mathrm{G})$ ratio changes as expected for modifying the $s p^{2}$-content by increasing the substrate temperature. For clarification, Figure 13a shows the refractive index and Figure 13b the absorption versus Raman $I(\mathrm{D}) / I(\mathrm{G})$ ratio.

For the phenomena of constant optical parameters by varying the substrate temperature, we found no analogy in the recent literature, and currently we have no proper explanation for this behavior. However, in our experiments, this effect was highly reproducible. In general, optical constants of DLC can by modified in different directions by changing the $s p^{2} / s p^{3}$ ratio, the crystallinity, the density, the amount of impurities, the angle of incidence of the plasma beam, the impinging particle energy, and surface roughness. Additionally, the refractive index and the absorption are closely connected via the Kramers-Kronig Relation. We can estimate that in the case of magnetic filtered deposition, different effects can compensate for each other, resulting in a more or less unchanging behavior of refractive index and absorption. 


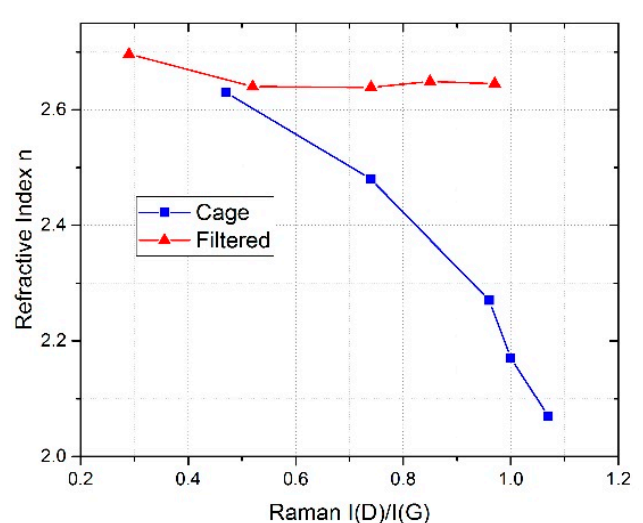

(a)

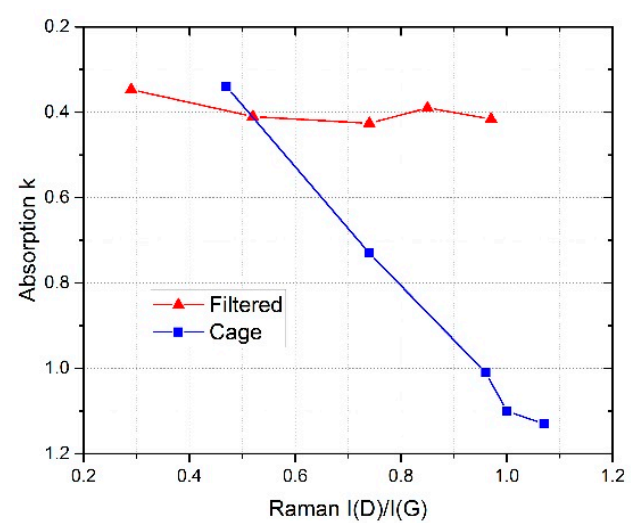

(b)

Figure 13. Raman $I(D) / I(G)$ ratio versus (a) refractive index and (b) absorption when using a cage (blue square) and magnetic filter (red square).

\section{Conclusions}

In summary, high current arc evaporation can be used for the production of different types of carbon coating. A magnetic macro particle filter can effectively reduce droplets and uncharged atoms, resulting in a dense and hard DLC coating, providing both a high refractive index $n$ and a low extinction coefficient $k$. These types of coatings can be used, for example, for thin barrier coatings in microelectronics and for ultra-thin protective coatings for hard disks. The $s p^{2} / s p^{3}$ ratio and the hardness can be adjusted by changing the substrate temperature during the deposition process. However, this does not influence the optical constants of the DLC films and, consequently, no black and hard carbon can be produced for reasons of the high refractive index and low extinction coefficient.

In this publication, we first combined the HCA technology with a metallic cage followed by a careful characterization and comparison. We found that by using a metallic cage the substrate temperature is closely connected to the optical contents. An increase of the substrate temperature will increase the layer absorption (extinction coefficient) and decrease the refractive index $n$. At $350{ }^{\circ} \mathrm{C}$, the coatings are black and exhibit a linear dispersion of the total reflection from UV to NIR, showing only weak wavelength dependence. Hence, these types of coatings can be used for optical applications with high mechanical strain such as lamellas for iris diaphragms. Even at a $350^{\circ} \mathrm{C}$ coating temperature, the hardness of the coating in the cage is comparable to that of standard wear-protective coatings like $\mathrm{TiN}, \mathrm{SiC}$, and WC.

Thanks to the metallic rotating cage, no sample holder is needed and the samples are coated homogeneously without any free regions or edges. Additionally, the internal stress is compensated by a simultaneous treatment of front and back sides inside the cage. Consequently, even thin foils can be coated without deformation.

Supplementary Materials: The following are available online at http://www.mdpi.com/2079-6412/9/5/345/s1, Figure S1: XPS spectra with its deconvoluted compounds for $s p^{3}$-carbon $(285.2 \mathrm{eV}), s p^{2}$-carbon $(284.4 \mathrm{eV})$ and C-O contamination $(286.5 \mathrm{eV})$ for different substrate temperatures; Figure S2: Deconvolution of Raman D band and G band (green line) and the resulting fitting curve (red line) for different substrate temperatures.

Author Contributions: Writing—original draft preparation, H.L. and M.E.; investigation H.L., M.E., J.K., M.L., C.V. and F.D.M.; writing-review and editing, M.E., J.K., M.L., C.V., F.D.M. and P.S.; visualization, H.L. and M.E.; supervision, S.S. and H.L.; project administration, S.S. and H.L.; funding acquisition, S.S.; conceptualization, P.S. and H.L.

Funding: We acknowledge support by the German Research Foundation and the Open Access Publication Funds of the TUAS Wildau. This work was funded by the Ministry of Economy and Energy (BMWi) of Germany in the frame of the Central Innovation Program for small and medium-sized businesses (ZIM) under contract number 16KN021332.

Acknowledgments: We acknowledge our project partner FAP Dresden GmbH for mechanical construction and the delivery of special vacuum parts. 
Conflicts of Interest: The authors declare no conflict of interest.

\section{References}

1. Robertson, J. Diamond-like amorphous carbon. Mater. Sci. Eng. R Rep. 2002, 37, 129-281. [CrossRef]

2. Hauert, R. A review of modified DLC coatings for biological applications. Diam. Relat. Mater. 2003, 12, 583-589. [CrossRef]

3. Hirakuri, K.; Yoshimura, M.; Friedbacher, G. Application of DLC films as masks for integrated circuit fabrication. Diam. Relat. Mater. 2003, 12, 1013-1017. [CrossRef]

4. Horiuchi, T.; Yoshida, K.; Kano, M.; Kumagai, M.; Suzuki, T. Evaluation of adhesion and wear resistance of DLC films deposited by various methods. Plasma Process. Polym. 2009, 6, 410-416. [CrossRef]

5. Erdemir, A.; Donnet, C. Tribology of diamond-like carbon films: Recent progress and future prospect. J. Phys. D Appl. Phys. 2006, 39, R311-R327. [CrossRef]

6. Khan, M.Z.U.; Bhowmick, S.; Lukitsch, M.J.; Alpasa, A.T. Effect of test atmosphere on the tribological behaviour of the tetrahedral amorphous carbon (ta-C) and fluorinated ta-C (ta-C-F) coatings against steel. Surf. Coat. Technol. 2017, 332, 382-390. [CrossRef]

7. Deng, X.; Kousaka, H.; Tokoroyama, T.; Umehara, N. Tribological behavior of tetrahedral amorphous carbon (ta-C) coatings at elevated temperatures. Tribol. Int. 2014, 75, 98-103. [CrossRef]

8. Dasca, J.M.; Ang, C.C.; Wong, C.A.; Cheng, Y.T.; Weiner, A.M.; Lev, L.C.; Konca, E. A comparison of five categories of carbon-based tool coatings for dry drilling of aluminum. Surf. Coat. Technol. 2006, 200, 2970-2977. [CrossRef]

9. Bhowmick, S.; Alpas, A.T. The performance of hydrogenated and non-hydrogenated diamond-like carbon tool coatings during the dry drilling of 319 Al. Int. J. Mach. Tools Manuf. 2008, 48, 802-814. [CrossRef]

10. Kim, Y.T.; Cho, S.M.; Choi, W.S.; Hong, B.; Yoon, D.H. Dependence of the bonding structure of DLC thin film on the deposition condition of PECVD method. Surf. Coat. Technol. 2003, 169, 291-294. [CrossRef]

11. Caschera, D.; Cossari, P.; Federici, F.; Kaciulis, S.; Mezzi, A.; Padeletti, G.; Trucchi, D. Influence of PE-CVD parameters on the properties of diamond-like carbon films. Thin Solid Films 2001, 519, 4087-4091. [CrossRef]

12. Grill, A.; Patel, V.; Cohen, S. Electrical resistivities of diamond-like carbon. Diam. Relat. Mater. 1994, 3, 281-284. [CrossRef]

13. Fedosenko, G.; Schwabedissen, A.; Engemann, J.; Braca, E.; Valentini, L.; Kenny, J.M. Pulsed PECVD deposition of diamond-like carbon films. Diam. Relat. Mater. 2002, 11, 1047-1052. [CrossRef]

14. Lin, C.R.; Wei, D.H.; Chang, C.K.; Liao, W.H. Optical properties of diamond-like carbon films for antireflection coating by RF magnetron sputtering method. Phys. Procedia 2011, 18, 46-50. [CrossRef]

15. Lackner, J.M.; Stottera, C.; Waldhauser, W.; Ebner, R.; Lenz, W.; Beutl, M. Pulsed laser deposition of diamond-like carbon coatings for industrial tribological applications. Surf. Coat. Technol. 2003, 174, 402-407. [CrossRef]

16. Scheibe, H.-J.; Siemroth, P.; Schöneich, B.; Mucha, A. DLC film preparation by LASER-ARC and properties study. Diam. Relat. Mater. 1992, 1, 98-103. [CrossRef]

17. Petereit, B.; Siemroth, P.; Schneider, H.-H.; Hilgers, H. High current filtered arc deposition for ultra-thin carbon overcoats on magnetic hard disks and read-write heads. Surf. Coat. Technol. 2003, 648, 174-175. [CrossRef]

18. Ferrari, A.C. Diamond-like carbon for magnetic storage disks. Surf. Coat. Technol. 2004, 180, 190-206. [CrossRef]

19. Scheibe, H.-J.; Schultrich, B.; Ziegele, H.; Siemroth, P. Deposition of superhard amorphous carbon films by pulsed arc sources. IEEE Trans. Plasma Sci. 1997, 25, 685-688. [CrossRef]

20. Liu, D.; Liu, Y.; Chen, B. Surface roughness of various diamond-like carbon films. Plasma Sci. Technol. 2006, 8, 701.

21. Pharr, G.M.; Oliver, W.C. Measurement of thin film mechanical properties using nanoindentation. Res. Soc. Bull. 1992, 17, 28-33. [CrossRef]

22. Pharr, G.M.; Callahan, D.L.; McAdams, S.D.; Tsui, T.Y.; Anders, S.; Anders, A.; Ager, J.W., III; Brown, I.G.; Bhatia, C.S.; Silva, S.R.P.; et al. Hardness, elastic modulus, and structure of very hard carbon films, produced by cathodicarc deposition with substrate pulse biasing. Appl. Phys. Lett. 1996, 68, 779-781. [CrossRef] 
23. Merel, P.; Tabbal, M.; Chaker, M.; Moisa, S.; Margot, J. Direct evaluation of the $\mathrm{sp}^{3}$ content in diamond-like-carbon films by XPS. Appl. Surf. Sci. 1998, 136, 105-110. [CrossRef]

24. Zavaleyev, V.; Walkowicz, J.; Greczynski, G.; Hultman, L. Effect of substrate temperature on properties of diamond-like films deposited by combined DC impulse vacuum-arc method. Surf. Coat. Technol. 2013, 236, 444-449. [CrossRef]

25. Ferrari, A.C.; Basko, D.M. Raman spectroscopy as a versatile tool for studying the properties of graphene. Nat. Nanotechnol. 2013, 8, 235. [CrossRef]

26. Pang, H.; Wang, X.; Zhang, G.; Chen, H.; Lva, G.; Yang, S. Characterization of diamond-like carbon films by SEM, XRD and Raman spectroscopy. Appl. Surf. Sci. 2010, 256, 6403-6407. [CrossRef]

27. Kanda, K.; Shimizugawa, Y.; Haruyama, Y.; Yamada, I.; Matsui, S.; Kitagawa, T.; Tsubakino, H.; Gejo, T. NEXAFS study on substrate temperature dependence of DLC films formed by Ar cluster ion beam assisted deposition. Nucl. Instrum. Methods Phys. Res. B 2003, 206, 880-883. [CrossRef]

28. Zhang, T.F.; Kim, K.-W.; Kim, K.H. Nitrogen-incorporated hydrogenated amorphous carbon film electrodes on Ti substrates by hybrid deposition technique and annealing. J. Electrochem. Soc. 2016, 163, E54-E61. [CrossRef]

29. Wang, L.; Northwood, D.O.; Nie, X.; Housden, J.; Spain, E.; Leyland, A.; Matthews, A. Corrosion properties and contact resistance of TiN, TiAlN and $\mathrm{CrN}$ coatings in simulated proton exchange membrane fuel cell environments. J. Power Sources 2010, 195, 3814-3821. [CrossRef]

30. Hones, P.; Sanjines, R.; Levy, F. Characterization of sputter-deposited chromium nitride thin films for hard coatings. Surf. Coat. Technol. 1997, 94, 398-402. [CrossRef]

31. Barshilia, H.C.; Prakash, M.S.; Jain, A.; Rajam, K.S. Structure, hardness and thermal stability of TiAlN and nanolayered TiAlN/CrN multilayer films. Vacuum 2005, 77, 169-179. [CrossRef]

32. Wolfe, D.E.; Singh, J. Microstructural evolution of titanium nitride (TiN) coatings produced by reactive ion beam-assisted, electron beam physical vapor deposition (RIBA, EB-PVD). J. Mater. Sci. 1999, 34, 2997-3006. [CrossRef]

33. Heeg, J.; Rosenberg, M.; Schwarz, C.; Barfels, T.; Wienecke, M. Optimised plasma enhanced chemical vapour deposition (PECVD) process for double layer diamond-like carbon (DLC) deposition on germanium substrates. Vacuum 2009, 83, 712-714. [CrossRef]

34. Písarík, P.; Jelínek, M.; Smetana, K., Jr.; Dvoránková, B.; Kocourek, T.; Zemek, J.; Chvostová, D. Study of optical properties and biocompatibility of DLC films characterized by $\mathrm{sp}^{3}$ bonds. Appl. Phys. A 2013, 112, 143-148. [CrossRef]

(C) 2019 by the authors. Licensee MDPI, Basel, Switzerland. This article is an open access article distributed under the terms and conditions of the Creative Commons Attribution (CC BY) license (http://creativecommons.org/licenses/by/4.0/). 